\title{
Morfoanatomía COMParada del vístago adulto de Conyza bonariensis var. BONARIENSIS Y C. BONARIENSIS VAR. ANGUSTIFOLIA (ASTERACEAE)
}

\author{
Comparative morphoanatomy of the adult shoot of Conyza bonariensis var. bonariensis and $C$. \\ bonariensis var. angustifolia (Asteraceae)
}

\author{
Beatriz Perez ${ }^{1}$ \& Nancy M. Apóstolo ${ }^{1}$
}

\begin{abstract}
Resumen: Conyza bonariensis, una especie medicinal e importante maleza nativa de Argentina, está representada por las variedades $C$. bonariensis var. bonariensis y $C$. bonariensis var. angustifolia. El objetivo del trabajo es comparar morfológica y anatómicamente los vástagos de ambas variedades en su etapa adulta, con el fin de contribuir a su identificación. Se analizaron ejemplares en estado vegetativo y reproductivo recolectados de poblaciones naturales. Los vástagos fueron divididos en tres zonas, superior, media e inferior, para caracterizar su morfoanatomía por medio de técnicas convencionales para microscopía óptica y electrónica de barrido. Entre las características halladas con valor diagnóstico se describen el tamaño, forma y margen de las hojas, tipo de indumento, densidad de tricomas y de estomas, forma de las células del clorénquima en los tallos y tipo de mesófilo. Muchas de estas características no fueron constantes entre las distintas zonas del vástago analizado, particularmente en el vástago vegetativo. Estos resultados indican que existen caracteres morfoanatómicos cuali- y cuantitativos que permiten la identificación taxonómica de $C$. bonariensis a nivel infraespecífico, los cuales, a su vez, pueden variar según el tipo y zona del vástago adulto analizado.
\end{abstract}

Palabras clave: Anatomía, Conyza, estructuras secretoras, malezas, plantas medicinales, tricomas.

Summary: Conyza bonariensis, a medicinal species and important weed native to Argentina, is represented by the varieties $C$. bonariensis var. bonariensis and $C$. bonariensis var. angustifolia The aim of this work is to compare the morphology and anatomy of the shoots of both varieties in their adult phase in order to contribute to their identification. Specimens in the vegetative and reproductive state collected from natural populations were analyzed. The shoots were divided into three zones, upper, middle and lower, to characterize their morphoanatomy using conventional techniques for light and scanning electron microscopy. Among the characteristics found to have diagnostic value are the size, shape and margin of the leaves, type of indumentum, density of trichomes and stomata, type of mesophyll and shape of the chlorenchyma cells in the stems. Many of these characteristics were not constant among the different zones of the shoot, particularly in the vegetative shoots. These results indicate that there are qualitative and quantitative morphoanatomical characters that allow the taxonomic identification of $C$. bonariensis at the infraspecific level, which in turn may vary depending on the type and zone of the adult shoot analyzed.

Key words: Anatomy, Conyza, medicinal plants, secretory structures, trichomes, weeds

1 PIEPVAS, Programa Interdisciplinario de Estudios en Plantas Vasculares. Departamento de Ciencias Básicas, Universidad Nacional de Luján, Ruta 5 y Av. Constitución, (6700) Luján, Buenos Aires, Argentina. Email: perezbea99@gmail.com, nancy.apostolo2@gmail.com 


\section{Introducción}

El género Conyza Less. (Asteraceae), parte de la tribu Astereae, está representado por 60100 especies de hierbas anuales o perennes distribuidas en todo el mundo (Sancho et al., 2014), aunque la mayoría crecen en las zonas templadas y subtropicales de América (Thébaud et Abott, 1995). En Argentina, habitan 23 especies entre las cuales se encuentra $C$. bonariensis (L.) Cronquist, una hierba nativa de América del Sur de amplia distribución en el territorio argentino (Sancho et al., 2014). Ha sido introducida en varios países de Africa, América del Norte, Asia, Europa y Oceanía, en muchos de los cuales se ha transformado en una especie invasora debido a su gran capacidad de colonización (Wu, 2007; Rapoport et al., 2009; CABI, 2021). La especie crece preferentemente en ambientes ruderales, como bordes de caminos y zonas urbanas, y como maleza en campos de cultivo.

Conyzabonariensis es conocida comúnmente como "carnicera", "yerba carnicera", "rama negra", "mata negra", "buva", "hairy fleabane", "wavy-leaved fleabane" y "flaxleaf fleabane" (Wu, 2007; Hurrell et al., 2011; Alonso et Desmarchelier, 2015). Presenta un ciclo de vida predominantemente anual y las semillas germinan, generalmente, en otoño e invierno, iniciando una etapa juvenil de roseta. En la primavera o verano siguiente, a partir de dichas rosetas se originan tallos adultos de aproximadamente $1 \mathrm{~m}$ de altura con inflorescencias paniculiformes o corimbiformes (Wu et al., 2010; Sancho et al., 2014). Actualmente, la especie comprende dos variedades, las que se pueden diferenciar por características vegetativas y reproductivas. Por un lado, C. bonariensis (L.) Cronquist var. bonariensis, que posee las hojas superiores lineares con margen entero y las inferiores angostamente obovadas con margen serrado o lobado, y por otro lado, C. bonariensis var. angustifolia (Cabrera) Cabrera, que presenta todas las hojas lineares con margen entero, entre las principales diferencias vegetativas (Sancho et al., 2014).

Las hojas, tallos y flores de $C$. bonariensis son empleadas en infusión o decocción como remedio hepatoprotector, diurético, béquico, pectoral, antiulceroso gástrico, antidiarreico, antihelmíntico, antihemorroidal y antidermatósico, entre otros usos. Las hojas frescas se utilizan en cataplasmas para desinfectar y curar heridas (Amat, 1983; Lahitte et al., 1998; Hurrell et al., 2011; Alonso et Desmarchelier, 2015). Estudios farmacológicos demostraron acción antimicótica, antibacterial, fitotóxica y antioxidante en ensayos in vitro en la especie (Luján et Pérez Corral, 2008; Manzano Santana et al., 2011; Shah et al., 2013; Thabit et al., 2015; Mussin et al., 2017). Por otro lado, ensayos in vivo en animales mostraron acción antiinflamatoria, hepatoprotectora, espasmolítica y espasmogénica en intestino delgado y citotóxica en carcinoma de piel (Manzano Santana et al., 2011; Bukhari et al., 2013; Saleem et al., 2014, 2015).

Sin embargo, mundialmente, C. bonariensis es considerada una importante maleza agrícola en diversos cultivos invernales y estivales, pasturas y huertos (Wu, 2007; Wu et al., 2010; Fernández et al., 2016). Además, se hallan citados biotipos resistentes a diversos agroquímicos, como el glifosato, en Argentina, Brasil, Colombia, España, Estados Unidos, Grecia, Israel, Portugal y Sudáfrica (Heap, 2020)

La identificación taxonómica de las especies de Conyza resulta problemática debido a la falta de estudios sistemáticos del género, la hibridación interespecífica, el polimorfismo y la existencia de variedades en varias especies (Thébaud et Abott, 1995; Urdampilleta et al., 2005a, b). Se ha abordado la sistemática comparada de varias especies del género Conyza, incluyendo a $C$. bonariensis, sobre la base de características citogenéticas, fitoquímicas y morfológicas de ejemplares en la etapa reproductiva y, minoritariamente, en la etapa juvenil (Amat, 1991; Urdampilleta et al., 2005a; Diez de Ulzurrun et al., 2018). Entre los caracteres morfológicos, Urdampilleta et al. (2005b) determinaron que el tipo de indumento de órganos vegetativos y reproductivos permite diferenciar algunas especies de Conyza. Los estudios previamente mencionados han considerado a C. bonariensis a nivel de especie o de su variedad tipo. Solo Amat (1991) comparó las variedades de C. bonariensis en 
un estudio quimiosistemático de un grupo de especies de Conyza, donde incluyó, además, la descripción anatómica de ambas variedades. Por otro lado, se han efectuado estudios anatómicos de aspectos generales de la raíz, tallo y hoja de $C$. bonariensis, los cuales no consideran ambas variedades de la especie (Procópio et al., 2003; Freire et al., 2005; Arambarri et al., 2013; Colares et al., 2014; Hernández et al., 2015). Todos estos autores analizaron solo una zona del vástago.

Estudios morfoanatómicos contribuirán a la determinación taxonómica y caracterización de las variedades de C. bonariensis. Por otro lado, la identificación de caracteres diagnósticos será útil para el control de la calidad y genuinidad de drogas vegetales comercializadas de la especie. El objetivo de este trabajo es realizar un análisis morfológico y anatómico comparado del vástago de $C$. bonariensis var. bonariensis y C. bonariensis var. angustifolia, incluyendo distintas zonas de los tallos adultos y tipos de hojas presentes en los mismos.

\section{Materiales y Métodos}

Los ejemplares de $C$. bonariensis var. bonariensis y $C$. bonariensis var. angustifolia analizados fueron recolectados de dos poblaciones naturales de la ciudad de Luján, provincia de Buenos Aires, y depositados en LP.

Conyza bonariensis var. angustifolia. ARgentinA. Buenos Aires: Pdo. Luján, predio Universidad Nacional de Luján, 343'58'S, 5906'54'W, $21 \mathrm{~m}, 17-\mathrm{II}-2016$, Costaguta 206 (LP).

Conyza bonariensis var. bonariensis. ARGENTINA. Buenos Aires: Pdo. Luján, predio Universidad Nacional de Luján, 34 33'58'S, 5906'54'W, 21 m, 17-II-2016, Costaguta 202 (LP).

De cada variedad se seleccionaron al azar en cada población seis ejemplares adultos en estado vegetativo antes de la floración y seis ejemplares en estado florífero o reproductivo. Los vástagos vegetativos presentaron una altura de 0,5-0,8 m (con 40-60 nudos, aproximadamente). Debido a que se observó variación en el tamaño y morfología foliar a lo largo del tallo de los ejemplares, los mismos fueron divididos y cortados en tres zonas: superior, media e inferior, con el fin de caracterizar todos los niveles del vástago. La zona superior comprendía desde el ápice hasta aproximadamente el nudo 20; la zona inferior, los 15 nudos desde la base o cuello del vástago; y la zona media, los nudos restantes entre ambas secciones anteriormente mencionadas.

La altura de los vástagos en estado florífero fue de $0,6-1,1 \mathrm{~m}$ e incluían una inflorescencia de $0,25-0,5 \mathrm{~m}$ en su parte terminal. Por debajo de dicha inflorescencia se encontraba la zona vegetativa con características similares a las observadas en los vástagos en estado vegetativo antes de la floración. Por lo tanto, en estos vástagos floríferos se analizó solo la zona florifera propiamente dicha o inflorescencia secundaria. Para ello, se dividió dicha inflorescencia en tres zonas: superior, justo por debajo del pedúnculo del capítulo terminal $\mathrm{y}$ hasta el primer nudo del tallo o raquis principal; inferior, 5 nudos próximos a la zona vegetativa; y media, nudos restantes entre las dos zonas anteriormente mencionadas. De estas zonas se obtuvieron muestras del tallo principal y de las hojas o brácteas de dicho tallo.

Las muestras de las distintas zonas de los vástagos fueron fijadas en FAA (formaldehído: ácido acético: alcohol etílico $96^{\circ}$ : agua destilada, 2:1:10:7). Secciones internodales del tallo y, al menos, tres hojas de cada zona del vástago vegetativo y de la inflorescencia fueron incluidas en parafina y cortadas con micrótomo rotatorio Microm HM 325 en forma transversal, longitudinal o paradermal, según el órgano analizado. Los cortes fueron coloreados con safranina $\mathrm{y}$ verde rápido $\mathrm{y}$ montados en resina sintética Entellan ${ }^{\mathbb{R}}$, según metodología convencional ( $\mathrm{D}^{\prime}$ Ambrogio de Argüeso, 1986; Zarlavsky, 2014).

Por otro lado, muestras de tallos y hojas de las diferentes zonas de los vástagos analizados fueron observadas con microscopio electrónico de barrido Philips XL30 TMP New Look (Museo Argentino de Ciencias Naturales "Bernardino Rivadavia"). Para ello, las muestras fueron deshidratadas con una 
serie ascendente de alcoholes, secadas con punto crítico y metalizadas con oro-paladio (D’Ambrogio de Argüeso, 1986).

También fueron realizadas muestras de epidermis de las hojas y los tallos de las diferentes zonas de los vástagos frescos mediante la técnica de peeling. Las epidermis obtenidas fueron clarificadas con hipoclorito de sodio $50 \%$, coloreadas con safranina $1 \%$ y montadas en gelatina-glicerina (Zarlavsky, 2014).

Para la identificación de almidón se realizó la prueba histoquímica de Lugol $\left(\mathrm{I}_{2}-\mathrm{KI}\right)$ en cortes de tallos frescos realizados a mano libre. La presencia de cristales fue determinada mediante el uso de un microscopio UNICO equipado con filtro polarizador y cámara digital Moticam. Las observaciones y fotomicrografías de campo claro fueron efectuadas con un microscopio óptico Nikon Eclipse E200 con cámara digital Moticam adosada.

Los tricomas se clasificaron según Ramayya (1962) y los tipos de estomas según los criterios de Metcalfe et Chalk (1979). Los espacios secretores se describieron según Fahn (1988).

Además, se realizó un análisis cuantitativo de la densidad de tricomas y de estomas en ambas epidermis de las hojas, y de la densidad de tricomas en el tallo, para cada zona del vástago vegetativo en tres de los ejemplares seleccionados de cada variedad de C. bonariensis. La densidad de tricomas se realizó sobre la base de todos los tipos encontrados. La determinación de los parámetros ser realizó en, al menos, seis campos ópticos al azar por preparado. Los resultados fueron analizados mediante ANOVA y test de Tukey $(\mathrm{p} \leq 0,05)$ con SPSS 15.0 .

\section{Resultados}

\section{Morfología del vástago adulto}

Los tallos adultos vegetativos y de la inflorescencia secundaria (capitulescencia) de ambas variedades de $C$. bonariensis son costados y pubescentes (Fig. 1A-D, G). Los tallos vegetativos son simples o poco ramificados. Las inflorescencias son cimas de capítulos de aspecto paniculiforme o corimbiforme, frondosas, formadas por un eje principal y pocos órdenes de ramificación. Los capítulos poseen pedúnculos bracteados (Fig. 1G)

Independientemente de la variedad, tipo de vástago adulto y zona de los mismos, todas las hojas son simples, sésiles, alternas, pubescentes, con base atenuada en pseudopecíolo y ápice agudo con mucrón (Fig. 1E, F, H, I). Sin embargo, el tamaño, forma y margen de las hojas varían gradualmente a lo largo del tallo vegetativo, siendo estos cambios más marcados en la población estudiada de $C$. bonariensis var. bonariensis (Fig. 1E, F). En ambas variedades de $C$. bonariensis, el tamaño de las hojas aumenta desde la zona inferior hacia la zona media del tallo vegetativo, pero desde esta zona disminuyen en su tamaño hacia la zona superior. Las hojas de C. bonariensis var. bonariensis presentan mayores dimensiones que las de $C$. bonariensis var. angustifolia. Respecto a la forma de las hojas del vástago vegetativo de $C$. bonariensis var. bonariensis, las de la zona inferior son obovadas, las de la zona media son oblanceoladas, angostamente oblanceoladas o elípticas, y las de la zona superior son lineares. Asimismo, las hojas inferiores y superiores más cercanas al ápice tienen el margen entero, mientras que el resto de las hojas tiene margen serrado con 2-6 dientes por hemilámina. El número de dientes del margen aumenta hacia la zona media y desde aquí disminuye hacia la zona superior del tallo. En C. bonariensis var. angustifolia, las hojas de las zonas inferior y media del tallo vegetativo son angostamente oblanceoladas o lineares, con algún diente en el margen o sin ellos, mientras que las de la zona superior son lineares de margen entero y usualmente ondulado.

Las hojas de la inflorescencia (brácteas) de ambas variedades de $C$. bonariensis son lineares, de menor tamaño que las del tallo vegetativo, y más pequeñas hacia la parte superior de la inflorescencia (Fig. 1H, I). El margen de las hojas de la inflorescencia es entero, aunque se observa margen ondulado en algunas hojas de $C$. bonariensis var. angustifolia. 

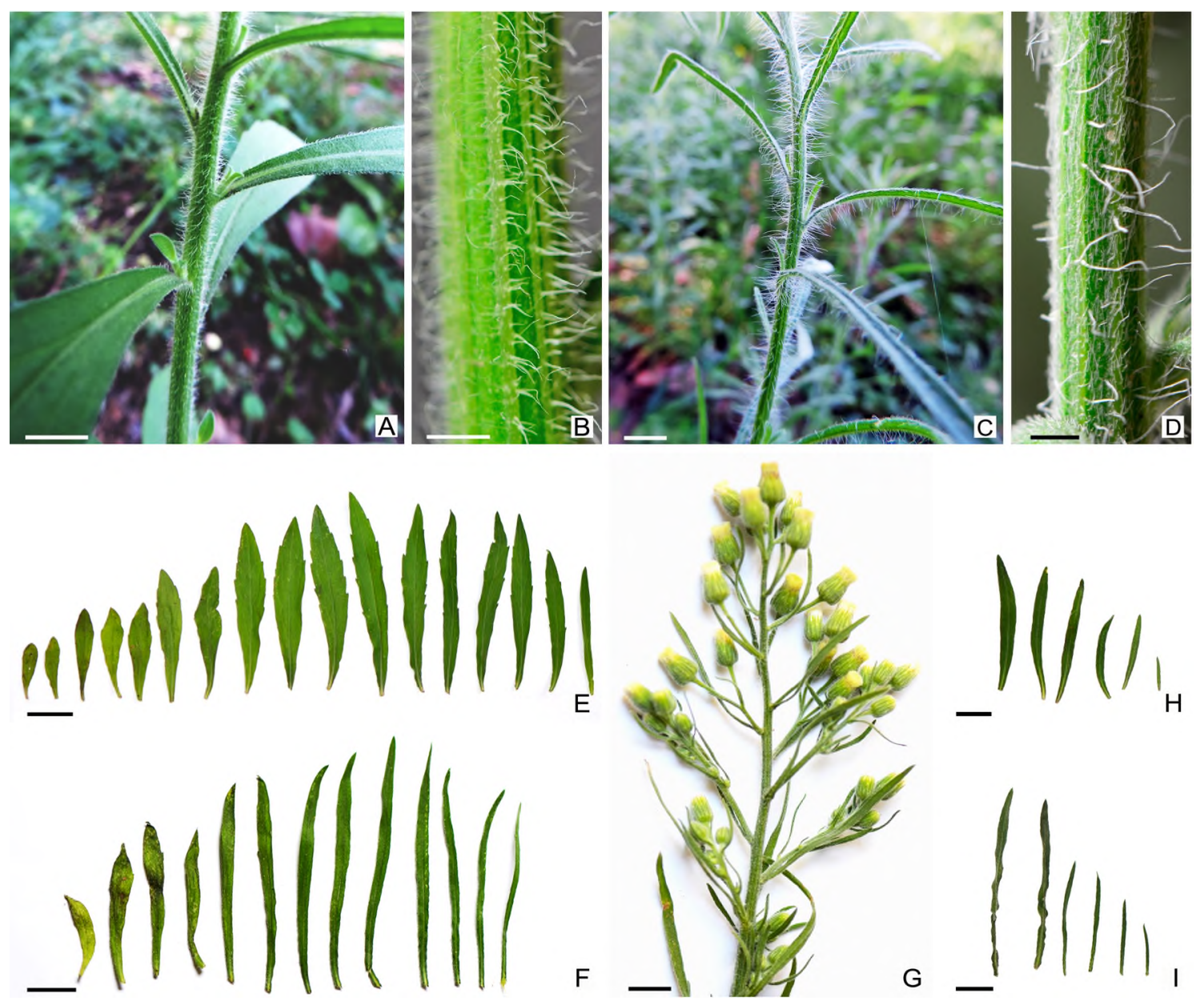

Fig. 1. Vástago adulto de Conyza bonariensis. A-F: Vástago vegetativo. A, B: C. bonariensis var. bonariensis. A: Aspecto general. B: Detalle del indumento. C, D: C. bonariensis var. angustifolia. C: Aspecto general. D: Detalle del indumento. E-F: Hojas desde la zona inferior (izquierda) a la superior del tallo. E: C. bonariensis var. bonariensis. F: C. bonariensis var. angustifolia. G-I: Vástago de la inflorescencia secundaria. G: Parte terminal del tallo principal, C. bonariensis var. angustifolia. H, I: Hojas desde la zona inferior (izquierda) a la superior del tallo principal. H: $C$. bonariensis var. bonariensis. I: C. bonariensis var. angustifolia. Barras: A, C, F-I: $1 \mathrm{~cm}$; B, D: $2 \mathrm{~mm}$; E: $2 \mathrm{~cm}$.

Fig. 1. Adult shoot of Conyza bonariensis. A-F: Vegetative shoot. A, B: C. bonariensis var. bonariensis. A: General view. B: Detail of the indumentum. C, D: C. bonariensis var. angustifolia. C: General view. D: Detail of the indumentum. E-F: Leaves from the lower (left) to the upper zone of the stem. E: C. bonariensis var. bonariensis. F: C. bonariensis var. angustifolia. G-I: Secondary inflorescence shoot. G: Terminal region of the main stem, C. bonariensis var. angustifolia. H, I: Leaves from the lower (left) to the upper zone of the main stem. H: C. bonariensis var. bonariensis. I: C. bonariensis var. angustifolia. Bars: A, C, F-I: $1 \mathrm{~cm} ; \mathrm{B}, \mathrm{D}: 2 \mathrm{~mm} ; \mathrm{E}: 2 \mathrm{~cm}$.

\section{Indumento del vástago adulto}

Los tricomas que recubren los vástagos vegetativos y de la inflorescencia de las dos variedades de C. bonariensis se disponen en toda la superficie caulinar y en ambas caras de las hojas, independientemente de la zona del vástago analizada. Se identificaron tres tipos de tricomas:

(1) Tricoma cónico simple (Fig. 2A-C). Eglandular. Base con (2-)4(-8) células grandes de disposición radiada (no siempre en los tallos), a veces sobreelevadas. 
Cuerpo uniseriado cónico, de 3-17 células (comúnmente 4-5 células en las hojas y 5 a más de 10 células en los tallos). Las 2-3 células proximales a la epidermis son más anchas y cortas (Fig. 2B); el resto de las células se van alargando hacia la parte distal del tricoma. Estas células del cuerpo son osteoladas, con paredes celulares laterales engrosadas, cutícula estriada en las células basales y proximales del cuerpo y verrucosa en las restantes (Fig. 2C). El contenido de las células es translúcido. La base y el cuerpo del tricoma pueden presentar cristales de oxalato de calcio en forma de drusas. Estos tricomas son muy abundantes en todas las partes de las hojas y los tallos. La longitud es variable, los más largos superan los 2 $\mathrm{mm}$ y son flexuosos. Los tricomas cónicos pueden ser adpresos y antrorsos (más o menos curvados en la dirección del ápice), o bien patentes. En el tallo vegetativo y en el de la inflorescencia de $C$. bonariensis var. bonariensis se observan, en un mismo sector del tallo, tricomas cónicos en su mayoría patentes o adpresos (Figs. 1B; 2D). Por otro lado, en $C$. bonariensis var. angustifolia se presentan, en el mismo sector del tallo, dos tipos de tricomas cónicos: tricomas adpresos $\mathrm{y}$ pequeños, más abundantes, y tricomas patentes muy largos, menos abundantes (Figs. 1D; 2E).

En las hojas, los tricomas cónicos más abundantes son los adpresos, más largos en la cara abaxial, especialmente en la vena media. En $C$. bonariensis var. angustifolia se observan tricomas patentes muy largos en los márgenes y en la cara abaxial de las hojas (Fig. 1C), mientras que en $C$. bonariensis var. bonariensis se pueden presentar tricomas patentes muy largos en las bases foliares, especialmente en las hojas de la inflorescencia.

(2) Tricoma flagelado aseptado (Fig. 2F). Eglandular. Célula basal en parte sobreelevada, generalmente con forma de cono truncado. Cuerpo del tricoma uniseriado, diferenciándose en una parte proximal y una distal. La parte proximal es cilíndrica, formada por (1-)3(-4) células en las hojas y (2-)3-4 células en los tallos, con paredes lisas. La célula terminal de esta parte del tricoma es más ancha que las restantes. La parte distal del tricoma está formada por una célula muy larga y angosta, con paredes gruesas. La cutícula generalmente es lisa, pudiendo ser estriada en la célula de la base del tricoma. Tanto la célula de la base como las de la parte proximal del cuerpo del tricoma pueden contener drusas. Estos tricomas son más pequeños que los tricomas cónicos (Fig. 1I) y, a diferencia de éstos, exhiben una longitud homogénea. Están en todas las partes de las hojas y tallos.

(3) Tricoma glandular vesicular biseriado, subtipo B (Fig. 2G, H). Base bicelular y cuerpo biseriado de 4-6 pares de células cuneadas de disposición subopuesta, tan anchas como largas. El par de células terminal es apenas más grande que el resto y de ápice redondeado. Las paredes de las células del tricoma son delgadas. La cutícula es lisa, o estriada en las células de la base. Se observa un espacio subcuticular a nivel del ápice de las dos células terminales (Fig. 2G). El contenido celular es denso y puede presentar drusas en las células de la base. Estos tricomas glandulares son menos abundantes y más pequeños que los tricomas eglandulares cónicos y flagelados (Fig. 2I). Se localizan principalmente en las hojas y tallos de la zona superior del vástago vegetativo y en todas las zonas del vástago de la inflorescencia.

La densidad de tricomas en los tallos vegetativos en ambas variedades de $C$. bonariensis es significativamente mayor en la zona superior y decrece hacia la zona inferior de los mismos (Tabla 1). Sin embargo, C. bonariensis var. bonariensis presenta diferencias en la densidad de tricomas entre las zona media e inferior del vástago, mientras que C. bonariensis var. angustifolia no exhibe diferencias en la cantidad de tricomas en los tallos entre ambas zonas del vástago mencionadas. Al comparar ambas variedades de C. bonariensis, se observa que en la zona superior y media de los tallos vegetativos la densidad de tricomas es mayor en $C$. bonariensis var. bonariensis, mientras que en la zona inferior de los tallos, la pubescencia es mayor en $C$. bonariensis var. angustifolia (Tabla 1). 


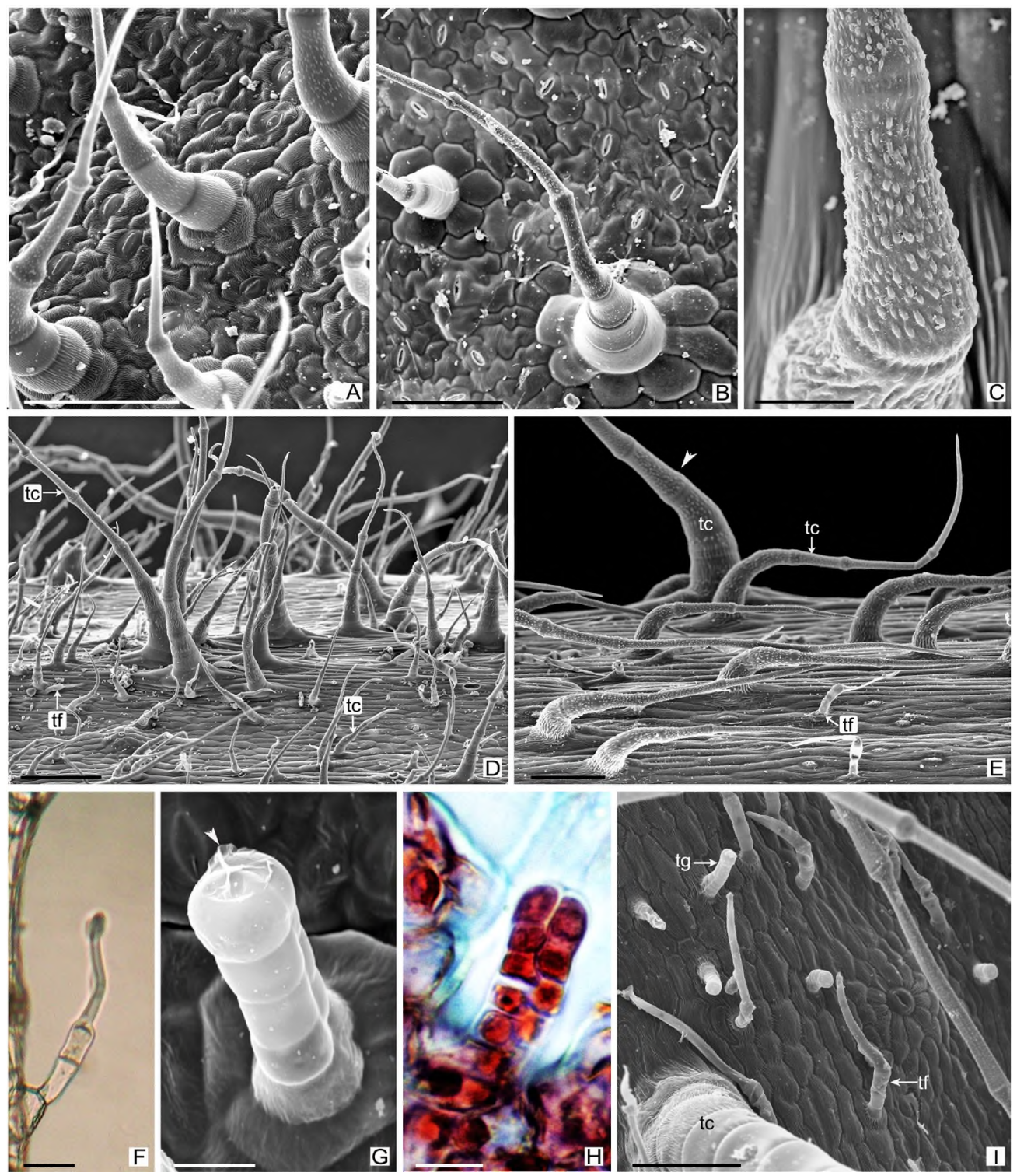

Fig. 2. Indumento del vástago adulto vegetativo de Conyza bonariensis. A-C: Tricomas cónicos simples de la hoja. A: Epidermis adaxial, CBB. B: Epidermis abaxial, CBA. C: Ornamentación en la cutícula. D: Tricomas cónicos simples patentes, zona media del tallo de CBB. E: Tricomas cónicos simples adpresos y uno patente (punta de flecha), zona media del tallo de CBA. F: Tricoma flagelado aseptado, hoja de CBB. G, H: Tricoma glandular vesicular biseriado, subtipo 3 , tallo de CBB. G: Tricoma con la cutícula rota en la zona apical (punta de flecha). H: Detalle. I: Vista superficial de la zona superior del tallo con los tres tipos de tricomas, CBB. Referencias: CBA: C. bonariensis var. angustifolia, CBB: C. bonariensis var. bonariensis, tc: tricoma cónico simple, tf: tricoma flagelado aseptado, tg: tricoma glandular vesicular biseriado, subtipo B. Barras: A, B, E, I: $100 \mu \mathrm{m} ; \mathrm{C}, \mathrm{F}: 20 \mu \mathrm{m} ; \mathrm{D}: 200 \mu \mathrm{m} ; \mathrm{G}, \mathrm{H}: 10 \mu \mathrm{m}$. Fig. 2. Indumentum of the adult vegetative shoot of Conyza bonariensis. A-C: Leaf simple conical trichomes. A: Adaxial epidermis, CBB. B: Abaxial epidermis, CBA. C: Cuticle ornamentation. D: Spreading simple conical trichomes, middle zone of the stem of CBB. E: Appressed and one spreading (arrowhead) simple conical trichomes, middle zone of the stem of CBA. F: Aseptate-flagellate trichome, leaf of CBB. G, H: Biseriate vesicular glandular trichome, subtype $\beta$, stem of CBB. G: Trichome with broken apical cuticle (arrowhead). H: Detail. I: Surface view of the upper zone of the stem with three types of trichomes, CBB. References: CBA: C. bonariensis var. angustifolia, CBB: C. bonariensis var. bonariensis, tc: simple conical trichome, tf: aseptate-flagellate trichome, tg: biseriate vesicular glandular trichome, subtype B. Bars: A, B, E, I: $100 \mu \mathrm{m} ; \mathrm{C}, \mathrm{F}: 20 \mu \mathrm{m} ; \mathrm{D}: 200 \mu \mathrm{m} ; \mathrm{G}, \mathrm{H}: 10 \mu \mathrm{m}$. 
Tabla 1. Densidad de tricomas y de estomas en hojas y tallo en tres zonas (superior, media e inferior) del vástago vegetativo de Conyza bonariensis var. bonariensis y C. bonariensis var. angustifolia (valores expresados por $\mathrm{mm}^{2}$, media \pm desvío estándar). Letras minúsculas distintas indican diferencias significativas entre las caras de una misma hoja. En una misma variedad, letras mayúsculas distintas indican diferencias significativas entre la misma cara foliar de las hojas de las tres zonas del vástago. Asteriscos indican diferencias significativas entre los correspondientes parámetros de las dos variedades (ANOVA y test de Tukey, $\mathrm{p} \leq 0,05$ ).

Table 1. Density of trichomes and density of stomata in leaves and stem in three zones (upper, middle and lower) of the vegetative shoot of Conyza bonariensis var. bonariensis and C. bonariensis var. angustifolia (values expressed per $\mathrm{mm}^{2}$, mean \pm standard deviation). Different lowercase letters indicate significant differences between both faces of a leaf. For each variety, different capital letters indicate significant differences among the same leaf surface of the leaves of the three zones of the stem. Asterisks indicate significant differences between the corresponding parameters of the two varieties (ANOVA and Tukey test, $p \leq 0.05$ ).

\begin{tabular}{|c|c|c|c|c|c|c|c|c|c|c|c|c|c|c|c|c|}
\hline \multirow{3}{*}{$\begin{array}{c}\text { Órgano } \\
\text { Hoja/cara adaxial }\end{array}$} & \multirow{3}{*}{$\begin{array}{c}\text { Zona del } \\
\text { vástago }\end{array}$} & \multicolumn{8}{|c|}{$\begin{array}{c}\text { Conyza bonariensis var. } \\
\text { bonariensis }\end{array}$} & \multicolumn{7}{|c|}{$\begin{array}{c}\text { Conyza bonariensis var. } \\
\text { angustifolia }\end{array}$} \\
\hline & & \multicolumn{4}{|c|}{ tricomas } & \multicolumn{4}{|c|}{ estomas } & \multicolumn{3}{|c|}{ tricomas } & \multicolumn{4}{|c|}{ estomas } \\
\hline & & $\begin{array}{l}113,6 \\
\pm 9,5\end{array}$ & a & A & * & $\begin{array}{l}142,0 \\
\pm 7,5\end{array}$ & & & & $\begin{array}{r}70,7 \\
\pm 4,6\end{array}$ & a & A & & $\begin{array}{r}150,0 \\
\pm 18,8\end{array}$ & $b$ & A \\
\hline Hoja/cara abaxial & Superior & $\begin{array}{r}83,5 \\
\pm 2,9\end{array}$ & $b$ & A & * & $\begin{array}{l}182,2 \\
\pm 9,6\end{array}$ & a & & & $\begin{array}{r}49,4 \\
\pm 1,8\end{array}$ & $b$ & A & & $\begin{array}{l}183,2 \\
\pm 7,4\end{array}$ & a & A \\
\hline Hoja/cara adaxial & Media & $\begin{array}{r}40,1 \\
\pm 1,1\end{array}$ & $a$ & B & & $\begin{array}{r}96,5 \\
\pm 9,4\end{array}$ & & & & $\begin{array}{r}46,4 \\
\pm 2,9\end{array}$ & $a$ & B & * & $\begin{array}{l}114,5 \\
\pm 7,8\end{array}$ & $b$ & $\mathrm{~B}$ \\
\hline Hoja/cara abaxial & Media & $\begin{array}{r}28,5 \\
\pm 0,6\end{array}$ & $\mathrm{~b}$ & $\mathrm{~B}$ & & $\begin{array}{l}161,7 \\
\pm 8,9\end{array}$ & & & & $\begin{array}{r}39,6 \\
\pm 2,1\end{array}$ & $\mathrm{~b}$ & B & * & $\begin{array}{l}150,7 \\
\pm 5,8\end{array}$ & a & $\mathrm{B}$ \\
\hline Hoja/cara adaxial & Inferior & $\begin{array}{r}21,6 \\
\pm 1,1\end{array}$ & $\mathrm{~b}$ & C & & $\begin{array}{r}74,0 \\
\pm 6,6\end{array}$ & $b c$ & C & & $\begin{array}{r}32,4 \\
\pm 1,1\end{array}$ & $a$ & C & * & $\begin{array}{r}63,7 \\
\pm 4,6\end{array}$ & b & $\mathrm{C}$ \\
\hline Hoja/cara abaxial & Inferior & $\begin{array}{l}23,4 \\
\pm 0,4\end{array}$ & $a$ & C & & $\begin{array}{l}157,5 \\
\pm 6,2\end{array}$ & a & B & * & $\begin{array}{r}29,0 \\
\pm 0,9\end{array}$ & $\mathrm{~b}$ & C & * & $\begin{array}{l}129,0 \\
\pm 8,6\end{array}$ & a & C \\
\hline Tallo & Superior & $\begin{array}{l}278,8 \\
\pm 5,7\end{array}$ & & $A$ & * & & & & & $\begin{array}{r}62,3 \\
\pm 4,5\end{array}$ & & A & & & & \\
\hline Tallo & Media & $\begin{array}{r}41,9 \\
\pm 2,9\end{array}$ & & B & & & & & & $\begin{array}{r}38,2 \\
\pm 2,9\end{array}$ & & B & & & & \\
\hline Tallo & Inferior & $\begin{array}{r}34,5 \\
\pm 1,6\end{array}$ & & C & & & & & & $\begin{array}{r}38,1 \\
\pm 1,1\end{array}$ & & B & * & & & \\
\hline
\end{tabular}

Por otro lado, las hojas de las tres zonas de los vástagos vegetativos de ambas variedades de C. bonariensis registran mayores valores de densidad de tricomas en la cara adaxial, excepto en las hojas inferiores de $C$. bonariensis var. bonariensis, en las cuales se determinó mayor densidad de tricomas en la cara abaxial (Tabla 1). Además, en ambas variedades de $C$. bonariensis, la densidad de tricomas es mayor en las hojas superiores del vástago vegetativo. Las hojas superiores de $C$. bonariensis var. bonariensis exhiben mayor densidad de tricomas que las respectivas hojas de $C$. bonariensis var. angustifolia, mientras que las hojas de la zona media e inferior de los tallos de C. bonariensis var. angustifolia presentan mayor densidad de tricomas que las de C. bonariensis var. bonariensis (Tabla 1).

Anatomía del vástago adulto vegetativo

Tallo. La zona superior y media del tallo de las dos variedades de $C$. bonariensis presentan un transcorte circular costado, con 6-8 costillas mayores separadas por valles en los que se pueden encontrar costillas menores (Fig. 3B, E). La zona inferior del tallo tiene costillas poco marcadas o no presenta costillas (Fig. $3 G)$.

En vista superficial, las células epidérmicas en las costillas son alargadas, mientras que en 

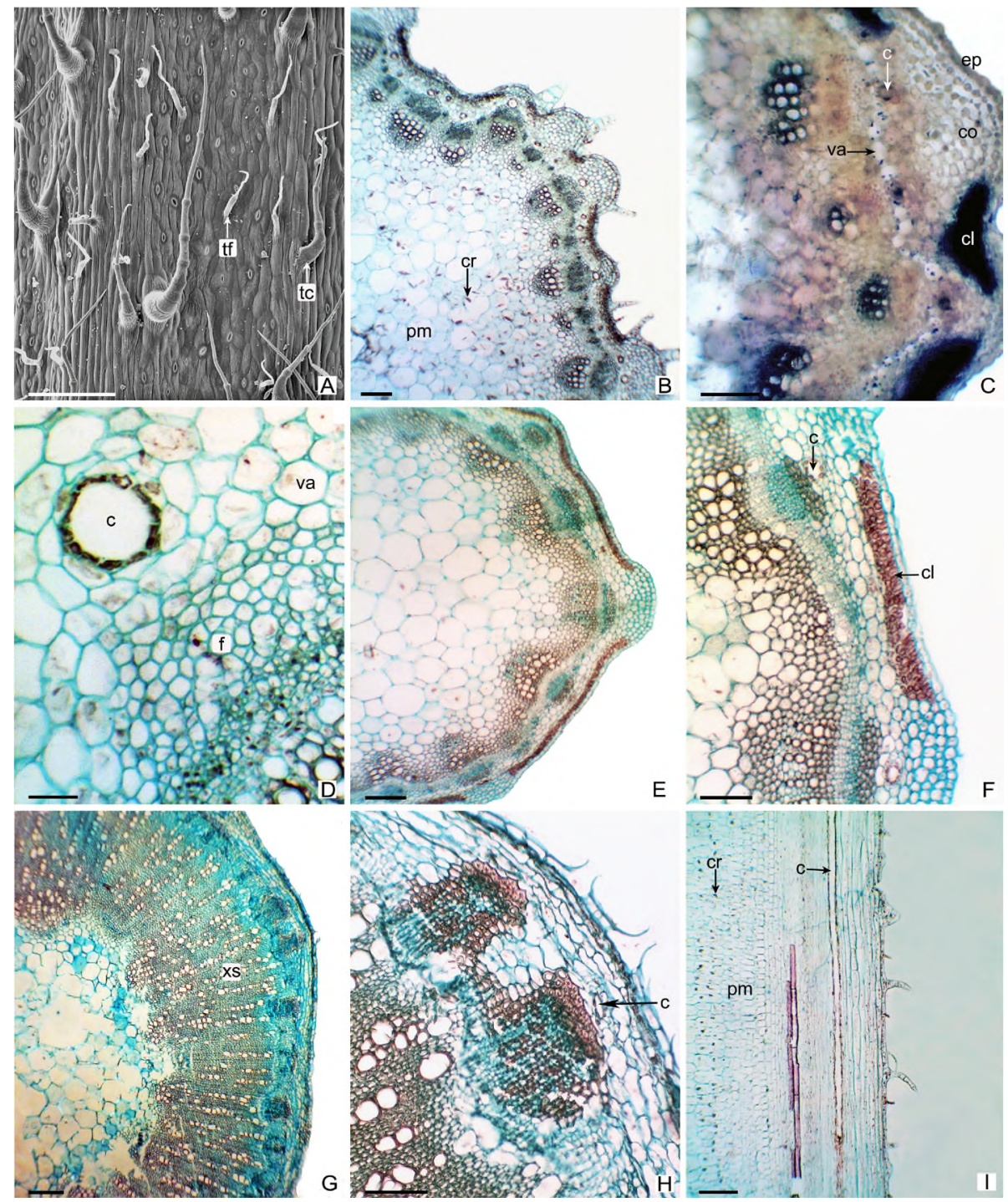

Fig. 3. Morfoanatomía del tallo adulto vegetativo de Conyza bonariensis. A: Micromorfología de la zona superior, CBA. B-D: CT de la zona superior con crecimiento primario, CBB. B: Costillas mayores y menores. C: Vaina amilifera (prueba de Lugol). D: Canal secretor en el parénquima cortical, sector de un haz vascular con fibras floemáticas. E, F: CT de la zona media con crecimiento secundario incipiente, CBA. E: Aspecto general. F: Detalle del clorénquima. G, H: CT de la zona inferior con crecimiento secundario, CBA. G: Aspecto general. H: Detalle. I: CL de la zona superior, CBB. Referencias: c: canal secretor, CBA: C. bonariensis var. angustifolia, CBB: C. bonariensis var. bonariensis, cl: clorénquima, CL: corte longitudinal, co: colénquima, cr: cristales, CT: corte transversal, ep: epidermis, f: fibras, pm: parénquima medular, tc: tricoma cónico simple, tf: tricoma flagelado aseptado, vp: vaina amilífera, xs: xilema secundario. Barras: A, E, G, I: $200 \mu \mathrm{m} ; \mathrm{B}, \mathrm{C}, \mathrm{F}, \mathrm{H}: 100 \mu \mathrm{m} ; \mathrm{D}: 20 \mu \mathrm{m}$.

Fig. 3. Morfoanatomy of the adult vegetative stem of Conyza bonariensis. A: Micromorphology of the upper zone, CBA. B-D: CT of the upper zone with primary growth, CBB. B: Major and minor ribs. C: Starch sheath (Lugol test). D: Secretory canal in cortical parenchyma and part of a vascular bundle with phloem fibers. E, F: CT of middle zone with initial secondary growth, CBA. E: General view. F: Detail of chlorenchyma. G, H: CT of the lower zone with secondary growth, CBA. G: General view. H: Detail. I: CL of the upper zone, CBB. References: c: secretory canal, CBA: C. bonariensis var. angustifolia, CBB: C. bonariensis var. bonariensis, cl: chlorenchyma, CL: longitudinal section, co: collenchyma, cr: crystals, CT: transverse section, ep: epidermis, f: fibers, pm: pith parenchyma, tc: simple conical trichome, tf: aseptate-flagellate trichome, vp: starch sheath, xs: secondary xylem. Bars: A, E, G, I: 200 m; B C, F, H: $100 \mu \mathrm{m} ; \mathrm{D}: 20 \mu \mathrm{m}$. 
los valles son más cortas, las paredes anticlinales son rectas y la cutícula es estriada (Figs. 2I; 3A). Los estomas están ubicados en los valles (Fig. 3A). En el corte transversal de la zona superior del tallo se evidencia una estructura primaria (Fig. 3B, C). La epidermis es uniestratificada, y sus células epidérmicas típicas son rectangulares anchas, con cutícula gruesa. Los estomas se encuentran a nivel de las restantes células epidérmicas. En la zona cortical y debajo de la epidermis se observa colénquima angular en las costillas y 2-4 capas de clorénquima en empalizada en los valles (Fig. 3B, C). El clorénquima puede extenderse a las costillas menores, reemplazando al colénquima. Las células del clorénquima de $C$. bonariensis var. angustifolia son isodiamétricas y apenas alargadas en sentido anticlinal, principalmente en el primer estrato del tejido. En ambas variedades, el resto de la zona cortical presenta 2-5 capas de parénquima, donde la más interna se destaca por sus células grandes con amiloplastos, formando una vaina amilifera que rodea los haces vasculares (Fig. 3C). El cilindro vascular presenta numerosos haces colaterales abiertos en eustela, con casquetes de fibras floemáticas poco engrosadas y lignificadas (Fig. 3D). La médula está compuesta por células parenquimáticas grandes y espacios intercelulares pequeños (Fig. 3B). Se observan canales secretores esquizógenos con epitelio uniseriado, de lumen circular u ovalado, en transcorte (Fig. 3B-D), y alargados, en corte longitudinal (Fig. 3I). Estas estructuras secretoras se localizan en la zona cortical adyacente al casquete de fibras del floema, pudiendo encontrarse uno o dos de ellos por haz vascular.

A diferencia de la zona superior del tallo, la zona media e inferior exhiben estructura secundaria, principalmente en el tejido vascular (Fig. 3E, H). El transcorte del tallo medio con crecimiento secundario incipiente muestra engrosamiento y lignificación de las fibras del floema primario y desarrollo de fibras xilemáticas y fibras interfasciculares (Fig. 3E, F). Al igual que en la zona superior del tallo, en la zona media de los tallos de C. bonariensis var. angustifolia, el primer estrato de clorénquima presenta las células alargadas anticlinalmente (Fig. 3F). En el tallo medio e inferior con sistema vascular secundario conspicuo se observan abundantes fibras en el xilema (Fig. 3G). Por otro lado, existen otras diferencias estructurales entre la zona superior e inferior del tallo. En el tallo inferior (Fig. 3G, H), la epidermis presenta células periclinalmente comprimidas y puede estar rasgada o deteriorada, comenzando a ser reemplazada por capas de súber de la peridermis. Las células del clorénquima en el tallo inferior son casi isodiamétricas en ambas variedades, siendo este tejido casi continuo alrededor del tallo, con solo algunas interrupciones de casquetes de colénquima laminar. Además, la vaina amilífera es poco o nada evidente, los canales esquizógenos se ven comprimidos y la médula está reducida en relación a la estructura primaria, aunque aún predomina su ancho en relación a la corteza, con células con paredes secundarias delgadas y la presencia de numerosas puntuaciones.

Las células de la epidermis y del clorénquima presentan drusas, más evidentes en la epidermis. Además, en las células del parénquima medular hay ráfides $\mathrm{y}$, en menor cantidad, cristales prismáticos y estiloides. Los cristales son abundantes en la zona superior del tallo (Fig. 3B, I)

Hojas. En las hojas de cualquier zona de los tallos de ambas variedades de $C$. bonariensis se destaca la vena media levemente convexa o plana en la cara adaxial y muy prominente hacia la cara abaxial (Fig. 4B, C). En general, la hemilámina tiende a formar un ángulo de $90^{\circ}$ con la vena media en C. bonariensis var. bonariensis, mientras que en $C$. bonariensis var. angustifolia se observa un ángulo obtuso entre la hemilámina y la vena media de la hoja (Fig. 4B, C). En todos los casos, las venas de mayor orden son levemente convexas hacia una o ambas caras (Fig. 4B, I).

Todas las hojas exhiben epidermis uniestratificada, con células isodiamétricas o algo alargadas y paredes anticlinales onduladas, en vista superficial (Figs. 2A, B; 4A). En transcorte, estas células epidérmicas son levemente más grandes en la cara adaxial que en la abaxial (Fig. 4D, F, I). La cutícula es gruesa y estriada (Figs. 2A; 4C). Los estomas se encuentran en ambas caras de la hoja a nivel de la epidermis (Fig. 4E). Son del tipo anisocítico y anomocítico, estos últimos rodeados por $2-5$ células vecinas (Fig. 4A). La densidad estomática es significativamente 


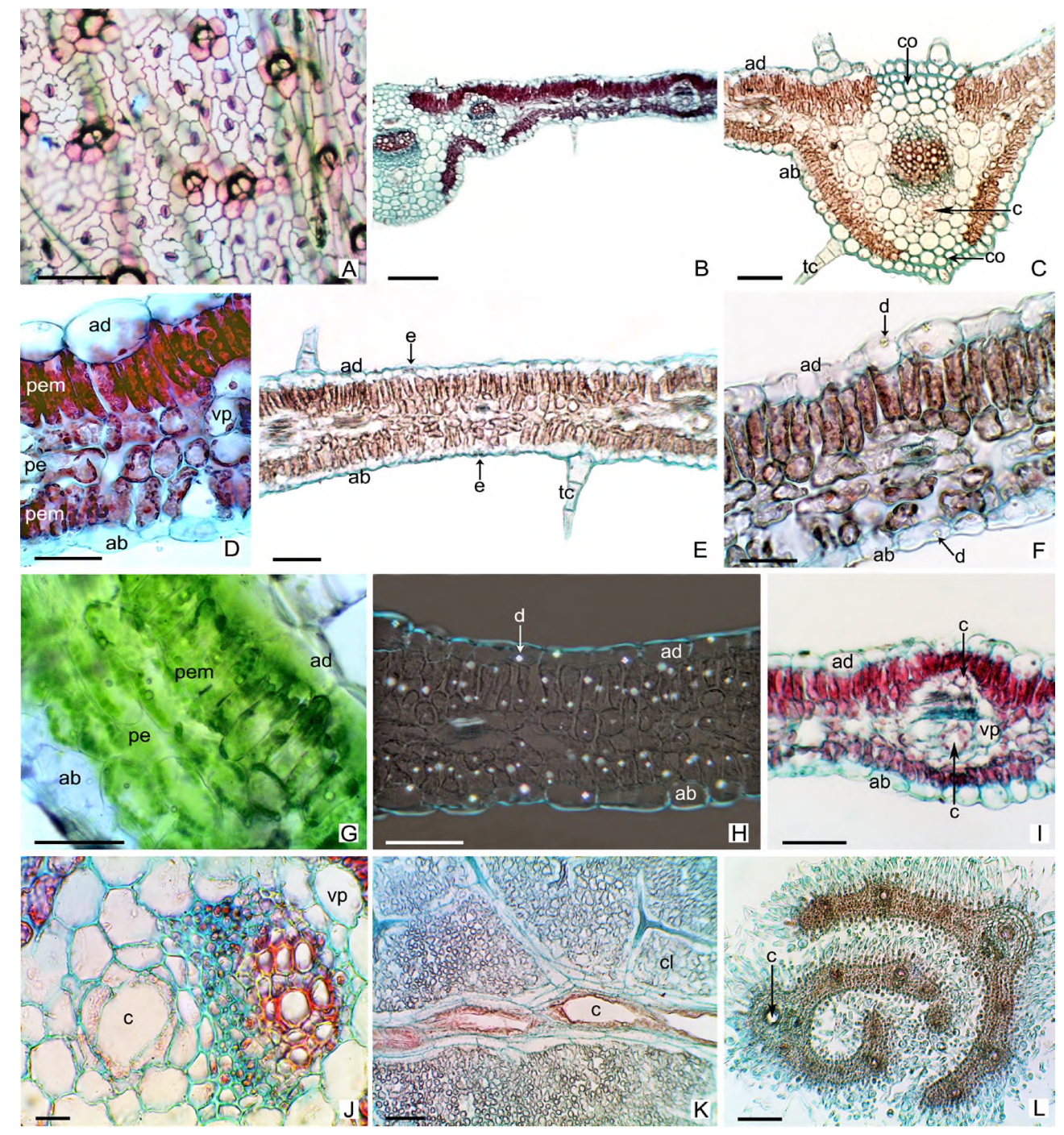

Fig. 4. Anatomía de las hojas adultas vegetativas de Conyza bonariensis. A: Vista superficial de epidermis adaxial de hoja superior, CBA. B-J: CT de hoja. B: Aspecto general de la hoja superior, CBB. C: Vena principal de la hoja media, CBA. D: Mesófilo isolateral en hoja superior, CBB. E: Aspecto general de hoja superior, mesófilo isolateral, CBA. F: Mesófilo isolateral en hoja media de CBB. G: Mesófilo dorsiventral en hoja inferior de CBB. H: Drusas en hoja superior de CBA (luz polarizada). I, J: Haces vasculares, CBB. K: Corte paradermal de hoja superior con hilera de canales secretores, CBB. L: CT de primordios foliares de CBB con canales secretores. Referencias: ab: epidermis abaxial, ad: epidermis adaxial, c: canal secretor, CBA: $C$. bonariensis var. angustifolia, $\mathrm{CBB}$ : C. bonariensis var. bonariensis, co: colénquima, CT: corte transversal, d: drusa, e: estoma, pe: parénquima esponjoso, pem: parénquima en empalizada, tc: tricoma cónico simple, vp: vaina de parénquima. Barras: A, C, E, H, I, K, L: $100 \mu \mathrm{m} ; \mathrm{B}: 200 \mu \mathrm{m} ; \mathrm{D}, \mathrm{F}, \mathrm{G}: 50 \mu \mathrm{m}$; J: $20 \mu \mathrm{m}$.

Fig. 4. Anatomy of the adult vegetative leaves of Conyza bonariensis. A: Surface view of adaxial epidermis of upper leaf, CBA. B-J: CT of leaf. B: General view of upper leaf, CBB. C: Midvein of middle leaf, CBA. D: Isolateral mesophyll in upper leaf, CBB. E: General view of upper leaf with isolateral mesophyll, CBA. F: Isolateral mesophyll in middle leaf of CBB. G: Dorsiventral mesophyll in lower leaf of CBB. H: Druses in upper leaf of CBA (polarized light). I, J: Vascular bundles, CBB. K: Paradermal section of upper leaf with a row of secretory canals, CBB. L: CT of leaf primordia with secretory canals, CBB. References: ab: abaxial epidermis, ad: adaxial epidermis, c: secretory canal, CBA: C. bonariensis var. angustifolia, CBB: C. bonariensis var. bonariensis, co: collenchyma, CT: transverse section, d: druse, e: stoma, pe: spongy parenchyma, pem: palisade parenchyma, tc: simple conical trichome, vp: parenchyma sheath. Bars: A, C, E, H, I, K, L: $100 \mu \mathrm{m} ; \mathrm{B}: 200 \mu \mathrm{m} ; \mathrm{D}, \mathrm{F}, \mathrm{G}: 50 \mu \mathrm{m} ; \mathrm{J}: 20 \mu \mathrm{m}$. 
mayor en la cara abaxial de las hojas de todas las zonas del tallo vegetativo de ambas variedades de $C$. bonariensis (Tabla 1). En C. bonariensis var. angustifolia la densidad estomática disminuye hacia la zona inferior del vástago en las respectivas epidermis foliares. En cambio, en $C$. bonariensis var. bonariensis, la densidad estomática es menor en las hojas medias que en las superiores. Las hojas de la zona inferior de esta variedad tienen menor densidad de estomas que las restantes hojas solo en su cara adaxial, mientras que en la cara abaxial, la densidad de estomas es semejante a la correspondiente cara de las hojas medias. Estas hojas inferiores de C. bonariensis var. bonariensis son las únicas que muestran diferencias significativas en su densidad estomática con respecto a las hojas de C. bonariensis var. angustifolia, la cual es mayor en ambas caras de la hoja (Tabla 1).

Las hojas de C. bonariensis var. bonariensis de la zona superior y media del tallo exhiben mesófilo isolateral, al igual que las hojas de todas las zonas del tallo de C. bonariensis var. angustifolia, siendo más notable en esta última variedad (Fig. 4D, F, H). Hacia la zona inferior del vástago de C. bonariensis var. bonariensis, el mesófilo tiende a ser dorsiventral (Fig. 4G). El clorénquima generalmente presenta 1(-2) capa de células en empalizada en ambas caras, usualmente discontinuas cuando son dos capas, más alargadas en el primer estrato hacia la cara adaxial (Fig. 4D, E). Sin embargo, las células del clorénquima en empalizada son más cortas y anchas en las hojas de la zona media inferior(Fig. 4F). Cuando el mesófilo es isolateral, se observan (1-)2(-3) capas de parénquima esponjoso entre ambos clorénquimas en empalizada, con células a menudo grandes, isodiamétricas o alargadas en sentido periclinal (Fig. 4D-F). En el caso de las hojas de la zona inferior del vástago de $C$. bonariensis var. bonariensis, el clorénquima en empalizada hacia la cara abaxial es discontinuo o puede faltar. Si está presente, las células son casi isodiamétricas, pues son muy cortas. Si está ausente, el mesófilo se torna dorsiventral por la presencia de un parénquima esponjoso (Fig. 4G).

Los haces vasculares de todas las hojas son colaterales y están rodeados por una vaina de parénquima (Fig. 4I, J), la cual no es evidente en el haz de la vena principal. En otras venas de mayor orden se observa colénquima hacia una o ambas epidermis. En la vena principal, no solo hay colénquima, sino también clorénquima y parénquima sin cloroplastos (Fig. 4B, C). La mayoría de los haces presentan un canal secretor esquizógeno, rara vez dos, de lumen circular u ovalado y epitelio uniseriado (Fig. 4C, I, J). Se localizan dentro del límite de la vaina de parénquima $\mathrm{y}$, en su mayoría, están adyacentes al floema $\mathrm{y}$, menos frecuentemente, al xilema. Raramente se observan haces vasculares con un canal xilemático y otro floemático (Fig. 4I). En corte paradermal, los canales secretores se observan relativamente cortos y dispuestos en hilera a lo largo de los haces (Fig. 4K). En los primordios foliares, estos canales son bien evidentes (Fig. 4L).

Las células de la epidermis y del clorénquima en empalizada exhiben drusas, siendo de mayor dimensión las localizadas en la epidermis (Fig. 4F, H). En el resto de los tejidos de las hojas, las drusas son escasas o están ausentes.

\section{Anatomía del vástago de la inflorescencia}

Tallo. La vista superficial del eje principal de la inflorescencia es semejante a la del tallo vegetativo. La anatomía de la zona superior del tallo florífero es similar a la del tallo vegetativo con crecimiento primario (Fig. 5A). Sin embargo, los ejes floríferos tienen abundante cantidad de fibras floemáticas y xilemáticas y fibras interfasciculares (Fig. 5A, B). Solo la zona superior del tallo de la inflorescencia más cercana al capítulo terminal tiene fibras poco engrosadas, tal como se observa en la zona superior del tallo vegetativo. Por otro lado, el clorénquima cortical en ambas variedades de $C$. bonariensis exhibe 1(-2) capas con células alargadas en sentido anticlinal (Fig. 5C). En la zona media e inferior del tallo florífero se observa crecimiento secundario vascular, tal como se ha descripto para las mismas zonas del vástago vegetativo. Sin embargo, la cantidad de cristales de oxalato de calcio en los tallos de la inflorescencia es menor que la observada en los tallos vegetativos.

Hojas. Las hojas más grandes de la inflorescencia de $C$. bonariensis var. bonariensis presentan la vena media y las de mayor orden prominentes, pero en las hojas más pequeñas de esta variedad y en las de C. bonariensis var. angustifolia las venas son poco marcadas (Fig. 5F). La vista superficial (Fig. 5D) y la anatomía 

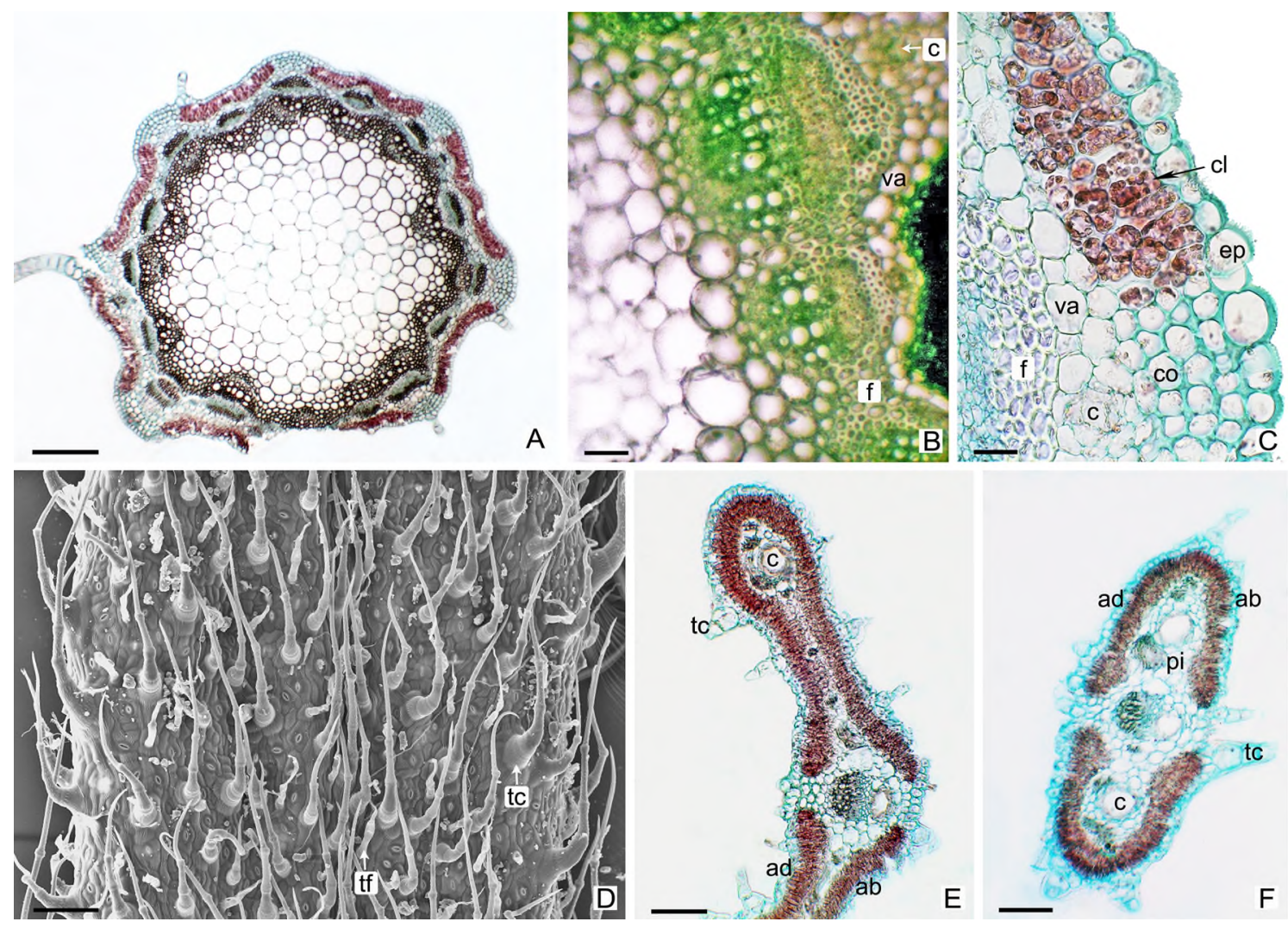

Fig. 5. Morfoanatomía del vástago de la inflorescencia de Conyza bonariensis. A-C: Zona superior del tallo principal con crecimiento primario, C. bonariensis var. angustifolia, CT. A: Aspecto general. B: Detalle de fibras fasciculares e interfasciculares. C: Detalle del clorénquima, con el primer estrato de células alargadas anticlinalmente. D-F: Hojas del eje principal. D: Vista de la superficie de hoja superior con numerosos tricomas, C. bonariensis var. bonariensis. E: Hoja media con mesófilo isolateral, C. bonariensis var. angustifolia, CT. F: Hoja superior con mesófilo isolateral con parénquima sin cloroplastos, C. bonariensis var. angustifolia, CT. Referencias: ab: epidermis abaxial, ad: epidermis adaxial, c: canal secretor, cl: clorénquima, co: colénquima, CT: corte transversal, ep: epidermis, f: fibras, pi: parénquima sin cloroplastos, tc: tricoma cónico simple, tf: tricoma flagelado aseptado, va: vaina amilifera. Barras: A: $200 \mu \mathrm{m} ; \mathrm{B}, \mathrm{C}: 20 \mu \mathrm{m} ; \mathrm{D}-\mathrm{F}: 100 \mu \mathrm{m}$.

Fig. 5. Morphoanatomy of the inflorescence shoot of Conyza bonariensis. A-C: Upper zone of the main stem with primary growth, C. bonariensis var. angustifolia, CT. A: General view. B: Detail of fascicular and interfascicular fibers $\mathrm{C}$ : Detail of chlorenchyma, with the first layer of anticlinally elongated cells. D-F: Leaves of the main stem. D: Surface view of upper leaf with numerous trichomes, C. bonariensis var. bonariensis. E: Middle leaf with isolateral mesophyll, C. bonariensis var. angustifolia, CT. F: Upper leaf with isolateral mesophyll with parenchyma without chloroplasts, C. bonariensis var. angustifolia, CT. References: ab: abaxial epidermis, ad: adaxial epidermis, c: secretory canal, c1: chlorenchyma, co: collenchyma, CT: transverse section, ep: epidermis, f: fibers, pi: parenchyma without chloroplasts, tc: simple conical trichome, tf: flagellate-aseptate trichome, va: starch sheath. Bars: A: 200 um; B, C: 20 um; D-F: 100 $\mu \mathrm{m}$.

de las hojas de la inflorescencia de las dos variedades de $C$. bonariensis muestran caracteres muy semejantes a los descriptos en las hojas de la zona superior del vástago vegetativo (Fig. $5 \mathrm{E}$, F). Sin embargo, en las hojas más pequeñas de la inflorescencia, el mesófilo isolateral presenta células parenquimáticas sin cloroplastos en lugar de parénquima esponjoso (Fig. 5F).

Sobre la base de las descripciones realizadas se presenta la Tabla 2, donde se resumen las principales diferencias morfoanatómicas entre las dos variedades de $C$. bonariensis. 
Tabla 2. Principales características morfoanatómicas diferenciales del vástago adulto de las variedades de Conyza bonariensis ( $C$. bonariensis var. bonariensis y C. bonariensis var. angustifolia).

Table 2. Main differential morphoanatomical characteristics of the adult shoot of the varieties of Conyza bonariensis (C. bonariensis var. bonariensis and C. bonariensis var. angustifolia).

\section{Característica} de las hojas del tallo vegetativo
Morfología y tamaño

\section{C. bonariensis var. bonariensis}

Hojas inferiores obovadas, margen entero. Hojas medias oblanceoladas, angostamente oblanceoladas 0 elípticas, margen serrado con 2-6 dientes por hemilámina. Hojas superiores lineares, margen con algún diente, las más cercanas al ápice con margen entero.

\section{Morfología de las hojas Margen entero}

de la inflorescencia

(brácteas)

\section{Indumento del tallo} vegetativo y de la inflorescencia

\section{Indumento de las hojas} vegetativas y de la inflorescencia

Densidad de tricomas en el tallo vegetativo

Densidad de tricomas en las hojas vegetativas

Clorénquima en el tallo vegetativo

\section{Densidad de} estomas en las hojas vegetativas

Mesófilo de las hojas vegetativas y de la inflorescencia
Tricomas cónicos en su mayoría patentes o adpresos en un mismo sector del tallo.

Tricomas patentes muy largos en las bases foliares, especialmente en las hojas de la inflorescencia.

Zona media e inferior del tallo con diferente densidad.

Zona superior y media con mayor densidad que en las respectivas zonas de los tallos de $C$. bonariensis var. angustifolia.

Hojas inferiores con mayor densidad en la cara abaxial (a diferencia del resto de las hojas).

Hojas superiores con mayor densidad que las respectivas hojas de C. bonariensis var. angustifolia.

Células isodiamétricas.

Mayor en las hojas superiores que en las medias. Hojas inferiores con menor densidad que las superiores y medias solo en la cara adaxial, cara abaxial igual a la abaxial de las hojas medias.

Hojas inferiores con mayor densidad que las respectivas hojas de $C$. bonariensis var. angustifolia.

Isolateral en las hojas de la inflorescencia y en las superiores y medias del vástago vegetativo. Dorsiventral en las hojas inferiores

\section{C. bonariensis var. angustifolia}

Hojas inferiores y medias

angostamente oblanceoladas o lineares, margen con algún diente o sin dientes. Hojas superiores lineares, margen entero, usualmente ondulado. Hojas de menor tamaño que las respectivas hojas de $\mathrm{C}$. bonariensis var. bonariensis.

Margen entero, a veces ondulado.

Tricomas cónicos adpresos y pequeños abundantes y tricomas patentes muy largos y menos abundantes en un mismo sector del tallo.

Tricomas patentes muy largos en el margen y cara abaxial.

Zona media e inferior del tallo con igual densidad.

Zona inferior con mayor densidad que en la respectiva zona de los tallos de

C. bonariensis var. bonariensis.

Hojas inferiores con mayor densidad en la cara adaxial (como el resto de las hojas).

Hojas medias e inferiores con mayor densidad que las respectivas hojas de C. bonariensis var. bonariensis.

Células alargadas anticlinalmente en el primer estrato del tejido en la zona superior y media del tallo.

Mayor en las hojas superiores y disminuye hacia las inferiores.

Isolateral, más notable que en $C$. bonariensis var. bonariensis. 


\section{Discusión y Conclusiones}

El análisis morfoanatómico del vástago adulto de $C$. bonariensis reveló diferencias cuali- y cuantitativas entre sus zonas superior, media e inferior, algunas de las cuales se interpretan como parte del desarrollo heteroblástico (Poethig, 1990). Este fenómeno es uno de los signos más evidentes de las transiciones entre las etapas del desarrollo por las que atraviesan muchas plantas: etapa juvenil, etapa adulta vegetativa (vástagos vegetativos) y etapa adulta reproductiva (vástagos floríferos) (Poethig, 1990; Kerstetter et Poethig, 1998; Huijser et Schmid, 2011). Las transiciones fueron menos graduales $\mathrm{y}$, por lo tanto, más marcadas, principalmente en las hojas de los vástagos, siendo más evidente en $C$. bonariensis var. bonariensis que en $C$. bonariensis var. angustifolia.

De esta manera, desde el punto de vista morfológico, los cambios de etapa de desarrollo más evidentes se registraron en el tamaño, forma y margen de las hojas. Al comienzo de la elongación de los tallos vegetativos se producen hojas transicionales que se van asemejando a las hojas de la zona media del vástago, las cuales podrían ser consideradas como las hojas típicas de la etapa adulta vegetativa. Asimismo, las hojas de la zona superior del vástago vegetativo podrían considerarse las hojas de transición hacia las hojas floríferas. Estas hojas se van asemejando o ya son iguales a las hojas de la inflorescencia, y su aparición anticipa la entrada en la etapa reproductiva. El polimorfismo que presentan algunas especies de Conyza (Urdampilleta et al., 2005a, b) podría estar relacionado con el desarrollo heteroblástico y la coexistencia de ejemplares de diferentes edades.

Desde el punto de vista anatómico, uno de los cambios de etapa de desarrollo más notables se presentó en la estructura del mesófilo. El mesófilo dorsiventral en las hojas inferiores de $C$. bonariensis var. bonariensis y el mesófilo isolateral con clorénquima de células bajas en $C$. bonariensis var. angustifolia transiciona hacia una estructura isolateral más marcada en las hojas de la zona media y superior del vástago vegetativo y en las hojas de la inflorescencia. Por un lado, desde un punto de vista general, según Esau (1985), la presencia de mesófilo isolateral es un carácter xeromórfico. Por otro lado, la intensidad lumínica baja inhibe el grado de desarrollo del parénquima en empalizada en ciertas especies y está más desarrollado en las hojas expuestas a la luz que en las de sombra (Paiva et al., 2003; Rossatto et Kolb, 2010). Por estas razones, las diferencias observadas en la estructura del mesófilo entre ambas variedades de C. bonariensis podrían interpretarse como ajustes fenotípicos en respuesta a diferentes condiciones microambientales que deben afrontar las plantas de cada variedad durante su crecimiento.

Una característica compartida por muchas especies de Asteraceae es la presencia de tricomas eglandulares y glandulares (Metcalfe et Chalk, 1979; Freire et al., 2007; Krak et Mráz, 2008; Perveen et al., 2016; Liesenfeld et al., 2019). Las dos variedades de C. bonariensis poseen los vástagos adultos pubescentes, así como las hojas juveniles de la etapa de roseta (Marzocca, 1997). A pesar de que existen trabajos previos sobre la anatomía de la especie (Procópio et al., 2003; Arambarri et al., 2013; Hernández et al., 2015), los mismos no proveen detalles de los tricomas encontrados y, menos aún, en ambas variedades de la especie. Los tres tipos detallados en el presente trabajo concuerdan con los descriptos por Amat (1991). No obstante, este autor no cita la presencia de tricomas glandulares en la epidermis de los tallos de C. bonariensis. Por su lado, Freire et al. (2005) describen solo tricomas cónicos en C. bonariensis var. bonariensis.

Las características del indumento de los tallos y hojas de $C$. bonariensis coinciden parcialmente con las presentadas por Urdampilleta et al. (2005b), quienes reportaron tricomas mayormente cortos, adpresos y pocos tricomas rígidos largos en el margen de las hojas y en las costillas de los tallos. En cuanto a la densidad de tricomas en una especie, ésta puede variar en una planta individual (Johnson, 1975; Dalin et al., 2008). Así, en el vástago vegetativo de ambas variedades de C. bonariensis, la densidad de tricomas fue mayor en las hojas y el tallo de la zona superior. Procópio et al. (2003) y Hernández et al. (2015) reportaron valores de densidad 
de tricomas que concuerdan con los resultados obtenidos en las hojas de las zonas inferior y media del vástago. Sin embargo, estos autores no especifican el estado de desarrollo de los ejemplares o la zona del tallo de donde extrajeron las muestras, por lo cual solo debería considerarse el valor absoluto como comparativo. Por su parte, Wu et Zhu (2014) determinaron valores de densidad de tricomas foliares de $C$. bonariensis más elevados que lo informado en el presente trabajo.

Los dos tipos de estomas, anomocítico y anisocítico, hallados en ambas variedades coinciden con lo informado por Hernández et al. (2015) para C. bonariensis. Las densidades estomáticas reportadas en trabajos previos (Procópio et al., 2003; Wu et Zhu, 2014; Hernández et al., 2015) son muy diferentes entre sí y no coinciden totalmente con los resultados obtenidos en el análisis de $C$. bonariensis var. bonariensis y $C$. bonariensis var. angustifolia. Estas discrepancias, al igual que en la densidad de tricomas, podrían deberse por ejemplo a la zona del tallo muestreada y también a la población estudiada (Wu et $\mathrm{Zhu}$, 2014).

Los tallos de las dos variedades de $C$. bonariensis son estructuralmente semejantes, excepto por la forma de las células del clorénquima en la zona superior y media del tallo vegetativo. Nuestros resultados coinciden con la descripción general de los tallos reproductivos de $C$. bonariensis realizada por Arambarri et al. (2013). Por el contrario, Amat (1991) describe al xilema primario formando un cilindro continuo y al floema dispuesto en forma casi continua. Por otra parte, los tallos floríferos de ambas variedades de $C$. bonariensis presentan numerosas fibras desde el comienzo de su crecimiento, diferenciándose así de los tallos vegetativos.

En trabajos previos, los espacios secretores fueron identificados en transcortes de tallos, hojas y raíces de $C$. bonariensis (Arambarri et al., 2013; Colares et al. 2014; Hernández et al. 2015) y, también, en hojas de C. sumatrensis (Retz.) E. Walker (Ekeke et Mensah, 2015). En cortes longitudinales de hojas y tallos de C. canadensis (L.) Cronquist, Lersten et Curtis (1987) describieron canales secretores cortos dispuestos en hilera, tal como se han observado en las hojas de ambas variedades de C. bonariensis. Sin embargo, en los tallos se presentaron canales relativamente alargados y solitarios. Es de destacar que se han encontrado canales secretores asociados no solo al floema, sino también al xilema, usualmente uno por haz vascular, pero también dos, caracteres no informados por otros autores. Esta disposición característica es similar a la que ha sido descripta en las hojas de otros representantes de la tribu Astereae, como Solidago canadensis L. (Lersten et Curtis, 1989) y S. chilensis Meyen (Perez et al., 2018).

En pruebas fitoquímicas en C. bonariensis se han identificado numerosos compuestos, como aceites esenciales, fenoles, flavonoides, quinonas, antocianinas, saponinas, glicósidos y taninos, siendo algunos de ellos los responsables de la actividad biológica de la especie (Maia et al., 2002; Manzano Santana et al., 2011; Zahoor et al., 2010; Saleem et al., 2014, 2015; Alonso et Desmarchelier, 2015; Thabit et al., 2015). Por otra parte, mediante pruebas histoquímicas, se han detectado aceites esenciales en el epitelio de los espacios secretores de los tallos de C. bonariensis (Arambarri et al., 2013). El tamaño de estos canales y su amplia distribución en el vástago adulto de ambas variedades de $C$. bonariensis indicarían importantes sitios de producción y almacenamiento de sustancias bioactivas.

La forma y distribución de los cristales de oxalato de calcio en los tejidos vegetales son características constantes a nivel de especie (Franceschi et Nakata, 2005). Las dos variedades de $C$. bonariensis examinadas presentaron igual tipo y distribución de cristales de oxalato de calcio, en concordancia con lo encontrado por Meric (2008) para la especie y para C. canadensis. Sin embargo, la cantidad de cristales presentes en la zona media e inferior del tallo vegetativo y en los ejes de la inflorescencia fue menor que en el resto del vástago. Algunos autores han informado la ausencia de cristales de oxalato de calcio en los tallos, hojas y raíces de $C$. bonariensis (Arambarri et al., 2013; Colares et al., 2014; Hernández et al., 2015). No obstante, la cantidad de cristales en los órganos puede variar debido a factores ambientales como la intensidad de luz, herbivoría y contenido de 
calcio en el medio (Franceschi et Horner, 1980; Franceschi et Nakata, 2005)

Conyza bonariensis puede crecer en una gran diversidad de suelos y de ambientes (Wu, 2007), sin embargo, los vástagos adultos de las dos variedades de la especie poseen algunos caracteres considerados como adaptaciones xeromórficas (Fahn, 1982): cutícula gruesa y estriada, pubescencia, hojas anfiestomáticas, numerosos estomas por unidad de superficie foliar, mesófilo isolateral y tejido esclerénquimático. Algunas de estas características se hacen más notables a medida que el vástago adulto se va desarrollando luego de la etapa invernal de roseta, en coincidencia con la entrada en la primavera-verano. Por otro lado, este aumento de caracteres xeromórficos podría explicar la menor susceptibilidad de C. bonariensis a ciertos herbicidas cuando se aplican en las hojas en etapas avanzadas de su desarrollo. Ustarroz et al. (2010) encontraron que la tolerancia al glifosato en las dos variedades de $C$. bonariensis es mínima en la etapa juvenil de roseta, aumenta durante la elongación de los tallos y es máxima al alcanzar la floración.

En el análisis morfoanatómico de distintas zonas del vástago adulto vegetativo $\mathrm{y}$ de la inflorescencia de $C$. bonariensis var. bonariensis y C. bonariensis var. angustifolia se han registrado similitudes y diferencias entre ambas variedades. Algunos caracteres no fueron constantes cuando se examinaron las distintas zonas del vástago de cada variedad o cuando se compararon las respectivas zonas entre variedades, particularmente en los vástagos vegetativos. Entre los principales caracteres diagnósticos se encuentran el tamaño, forma, y margen de las hojas, tipo de indumento, densidad de tricomas y estomas, forma de las células del clorénquima en los tallos y tipo de mesófilo. El indumento, junto con la morfología y tamaño foliar, permiten el reconocimiento de las variedades de forma rápida $\mathrm{y}$ práctica. $\mathrm{El}$ valor taxonómico de los tricomas fue utilizado anteriormente para separar especies del Conyza, por lo que sería importante extender este tipo de estudio a más especies del género. Por último, la variabilidad que presentan las características morfoanatómicas a lo largo del vástago debería ser tenida en cuenta al momento de detectar la presencia y/o genuinidad de fragmentos de drogas vegetales bajo el nombre de "yerba carnicera".

\section{Agradecimientos}

A la Lic. Mariana Costaguta por la colecta del material de herbario. A los pasantes de grado (PIR-UNLu) Christian N. Altamirano y Florencia Mansilla por su colaboración en tareas técnicas de laboratorio y de campo. Al Lic. Fabián Tricárico del Servicio de Microscopía Electrónica de Barrido del Museo Argentino de Ciencias Naturales "Bernardino Rivadavia" por sus servicios técnicos. Este trabajo fue financiado con un subsidio de investigación finalidad 3.5 del Departamento de Ciencias Básicas de la Universidad Nacional de Luján.

\section{Bibliografía}

Alonso, J. \& Desmarchelier, C. (2015). Plantas medicinales autóctonas de la Argentina: bases científicas para su aplicación en atención primaria de la salud. Corpus Libros Médicos y Científicos, Buenos Aires

Amat, A. G. (1983). Taxones de Compuestas bonaerenses críticos para la investigación farmacológica. Acta Farmacéutica Bonaerense 2: 23-36.

Amat, A. G. (1991). Revisión y enfoque quimiosistemático de las especies argentinas del género Conyza Less., con especial referencia al grupo C. albida-C. bonariensis-C. floribunda (Asteraceae-Astereae). Tesis Doctoral, Universidad Nacional de La Plata, Argentina. $225 \mathrm{pp}$.

Arambarri, A. M., Novoa, M. C., Hernández, M. P., Colares, M. N. \& Perrotta, V. G. (2013). Anatomía de Dicotiledóneas: tallos de hierbas terrestres medicinales rioplatenses (Buenos Aires, República Argentina). Bonplandia 22: 107-130. https://oi.org/10.30972/bon.2221240

Bukhari, I. A., Shah, A. J., Khav, R. A., Meo, S. A., Khan, A. \& GLllan, A. H. (2013). Gut modulator effects of Conyza bonariensis explain its traditional use in constipation and diarrhea. European Review for Medical and Pharmacological Sciences 17: 552558 . 
CABI. (2021). Conyza bonariensis. En Invasive Species Compendium. Wallingford, UK: CAB International. Disponible: http:/www.cabi.org/isc (Consulta 22/07/21).

Colares, M. N., Hernández, M. P., Novoa, M. C., Perrotta, V. G., Auguet, S. \& Arambarri, A. M. (2014). Anatomía comparada de raíces medicinales de hierbas terrestres rioplatenses (Buenos Aires, República Argentina). Dominguezia 30: 5-17.

Dalin, P., Ågren J., Buörkman, C., Huttunen P. \& KÄRKKÄINEN, K. (2008). Leaf trichome formation and plant resistance to herbivory. En ScHaller, A. (ed.), Induced plant resistance to herbivory, pp. 89-105. Springer, Dordrecht. https://doi.org/10.1007/978-1-4020-8182-8_4

D'Ambrogio de Argüeso, A. (1986). Manual de técnicas en histología vegetal. Hemisferio Sur, Buenos Aires.

Diez De Ulzurrun, P., Acedo, M. B., Garavano, M. E., Gianelli, V. \& Ispizúa, V. N. (2018). Caracterización morfológica de Conyza blakei, Conyza bonariensis var. bonariensis, Conyza sumatrensis var. sumatrensis y Conyza lorentzii en el sudeste bonaerense (Argentina). Boletín de la Sociedad Argentina de Botánica 53: 359-73. https://doi.org/10.31055/1851.2372.v53.n3.21311

EkeKe, C. \& Mensah, S. I. (2015). Comparative anatomy of midrib and its significance in the taxonomy of the family Asteraceae from Nigeria. Journal of Plant Sciences 10: 200-205. https://doi.org/10.3923/jps.2015.200.205

Esau, K. (1985). Anatomía de las plantas con semilla. Hemisferio Sur, Buenos Aires.

FAHN, A. (1982). Anatomía vegetal. Pirámide, Madrid.

Fayn, A. (1988). Secretory tissues in vascular plants. New Phytologyst 108: 229-257. https://doi.org/10.1111/j.1469-8137.1988.tb04159.x

Fernández O., Leguizamón, E. S. \& ACciaresi, H. A. (2016). Malezas invasoras de la Argentina II: descripción y reconocimiento. Universidad Nacional del Sur, Bahía Blanca.

Franceschi, V. R. \& Horner, H. T. (1980). Calcium oxalate crystals in plants. The Botanical Review 46: 361-427. https://doi.org/10.1007/BF02860532

Franceschi, V. R. \& Nakata, P. A. (2005). Calcium oxalate in plants: formation and function. Annual Review of Plant Biology 56: 41-71. https://doi. org/10.1146/annurev.arplant.56.032604.144106

Freire, S. E., Arambarri, A. M., Bayón, N. D., Sancho, G., Urtubey, E., Monti, C., Novoa, M. C. \& Colares, M. N. (2005). Epidermal characteristics of toxic plants for cattle from the Salado River basin
(Buenos Aires, Argentina). Boletín de la Sociedad Argentina de Botánica 40: 241-281.

Freire, S., Urtubey, E. \& Giuliano, D. A. (2007). Epidermal characters of Baccharis (Asteraceae) species used in traditional medicine. Caldasia 29: 23-38.

Heap, I. (2020). The international survey of herbicideresistant weed database. Online. Disponible: http:// www.weedscience.com/ (Consulta 09/09/20).

Hernández, M. P., Novoa, M. C., Colares, M. N., Perrotta, V. G., Nughes, L. M. \& Arambarri, A. M. (2015). Anatomía foliar de hierbas terrestres medicinales que crecen en la región rioplatense (Buenos Aires, Argentina). Bonplandia 24: 97-123 https://doi.org/10.30972/bon.242236

Huisser, P. \& Schmid, M. (2011). The control of developmental phase transitions in plants. Development 138: 4117-4129 https://doi.org/10.1242/dev.063511

Hurrell, J. A., Ulibarri, E., Arenas, P. M. \& Pochettino, M. L. (2011). Plantas de herboristería LOLA, Buenos Aires

Johnson, H. B. (1975). Plant pubescence: an ecological perspective. Botanical Review 41: 233-258. https://doi.org/10.1007/BF02860838

Kerstetter, R. A. \& Poethig, R. S. (1998). The specification of leaf identity during shoot development. Annual Review of Cell and Developmental Biology 14: 373-398. https://doi.org/10.1146/annurev.cellbio.14.1.373

KraK, K. \& Mráz, P. (2008). Trichomes in the tribe Lactuceae (Asteraceae) - taxonomic implications. Biologia 63: 616-630. https://doi.org/10.2478/s11756-008-0106-z

Lahitte, H. B., Hurrell, J. A. \& Belgrano, M. (1998). Plantas medicinales rioplatenses. LOLA. Buenos Aires

Lersten, N. R. \& Curtis, J. D. (1987). Internal secretory spaces in Asteraceae: a review and original observations on Conyza canadensis (tribe Astereae). La Cellule 74: 179-196.

Lersten, N. R. \& Curtis, J. D. (1989). Foliar oil reservoir anatomy and distribution in Solidago canadensis (Asteraceae, tribe Astereae). Nordic Journal of Botany 9: 281-287.

https://doi.org/10.1111/j.1756-1051.1989.tb01003.x

Liesenfeld, V., Gentz, P., Freitas, E. M. \& Martins, S. M. (2019). Morphological diversity of foliar trichomes in Asteraceae from Sand-fields of the Pampa biome, Rio Grande do Sul State, Brazil. Hoehnea 46: e752018. https://doi.org/10.1590/2236-8906-75/2018. 
Luján, M. C. \& Pérez Corral, C. (2008). Cribado para evaluar actividad antibacteriana y antimicótica en plantas utilizadas en medicina popular de Argentina. Revista Cubana de Farmacia 42. Disponible: http://scielo. sld.cu/scielo.php?script $=$ sci arttext\&pid $=$ S0034-75152008000200007\&lng $=$ es\& tlng=es (Consulta 06/11/20).

Maia, J. G. S., Silla, M. H. L. da, Zoghbi, M. das G. B. \& ANDRADE, E. H. A. (2002). Composition of the essential oils of Conyza bonariensis (L.) Cronquist. Journal of Essential Oil Research 14: 325-326. https://doi.org/ 10.1080/10412905.2002.9699871

Manzano Santana, P., Miranda, M., Gutiérrez, Y., García, G., Orellana, T. \& Orellana-Manzano, A. (2011). Efecto antiinflamatorio y antimicótico del extracto alcohólico y composición química del aceite de hojas de Conyza bonariensis (L.) Cronquist (canilla de venado). Revista Cubana de Plantas Medicinales 16: 13-23. Disponible: http://scielo. sld.cu/scielo.php?script=sci_arttext\&pid=S1028$47962011000100002 \& \operatorname{lng}=$ es\&tlng=es (Consulta 07/11/20).

MarzoccA, A. (1997). Vademécum de malezas medicinales de la Argentina: indígenas y exóticas. Orientación Gráfica Editora, Buenos Aires.

Meric, C. (2008). Calcium oxalate crystals in Conyza canadensis (L.) Cronq. and Conyza bonariensis (L.) Cronq. (Asteraceae: Astereae). Acta Biologica Szegediensis 52: 295-299.

Metcalfe, C. R. \& Chalk, L. (1979). Anatomy of the Dicotyledons. Systematic anatomy of the leaf and stem. Vol. I. Clarendon Press, Oxford.

Mussin, J. E., Manzano, P., Mangiaterra, M. \& Giusiano, G. (2017). Inhibitory activity of Conyza bonariensis (L.) Cronquist tincture against fungi and bacteria causing superficial infections. Revista Cubana de Plantas Medicinales 22. Disponible: http://www.revplantasmamedicinales.sld.cu/index. $\mathrm{php} / \mathrm{pla} /$ article/view/560 (Consulta 07/08/20).

Paiva, E. A. S., Isaias, R. M. dos S., Vale, F. H. A. \& QueIroz, C. G. DE S. (2003). The influence of light intensity on anatomical structure and pigment contents of Tradescantia pallida (Rose) Hunt. cv. purpurea Boom (Commelinaceae) leaves. Brazilian Archives of Biology and Technology 46: 617-624. https://doi.org/10.1590/S1516-89132003000400017

Perez, B., Carretton, D. M., Lus, B. A. \& Apóstolo, N. M. (2018). Anatomía del rizoma y de la parte basal, media y distal del vástago de Solidago chilensis var. chilensis (Asteraceae). Lilloa 55: 4966. https://doi.org/10.30550\%20/j.li1/2018.55.1/5
Perveen, A., Khan, M., Mansuri, S. \& Tabassum, T. (2016). Morphological studies on trichome of family Asteraceae. International Journal of Biology and Biotechnology 13: 177-182.

Poethig, R. S. (1990). Phase change and the regulation of shoot morphogenesis in plants. Science 250: 923930. https://doi.org/10.1126/science.250.4983.923

Procópio, S. O., Ferreira, E. A., Silva, E. A. M., Silva, A. A., Rurino, R. J. N. \& Santos, J. B. (2003). Estudios anatômicos de folhas de espécies de plantas daninhas de grande ocorrência no Brasil. III - Galinsoga parviflora, Crotalaria incana, Conyza bonariensis e Ipomoea cairica. Planta Daninha 21: 1-9.

https://doi.org/10.1590/S0100-83582003000100001

Ramayya, N. (1962). Studies on the trichomes of some Compositae. I. General structure. Bulletin of the Botanical Survey of India 4: 177-188.

Rapoport, E. H., Marzocca, A. \& Drausal, B. S. (2009). Malezas comestibles del Cono Sur y otras partes del planeta. INTA, Buenos Aires.

Rossatto, D. R. \& Kolb, R. M. (2010). Gochnatia polymorpha (Less.) Cabrera (Asteraceae) changes in leaf structure due to differences in light and edaphic conditions. Acta Botanica Brasilica 24: 605-612. http://doi.org/10.1590/s0102-33062010000300002

Saleem, M., Naseer, F., Ahmad, S., Nazish, A., Bukhari, F. R., Rehman, A. U., Khan, I. M., SADiQ, S. \& JAVED, F. (2014). Hepatoprotective activity of ethanol extract of Conyza bonariensis against paracetamol induced hepatotoxicity in swiss albino mice. American Journal of Medical and Biological Research 2: 124-127. http://doi.org/10.12691/ajmbr-2-6-2

Saleem, M., Naseer, F., Hussain, K. \& Alamgeer. (2015). Cytotoxic effect of methanol extract of Conyza bonariensis on DMBA-induced skin carcinogenesis: an in vivo study. Bangladesh Journal of Pharmacology 10: 467-474.

http://doi.org/10.3329/bjp.v10i2.23063

Sancho, G., Viera Barreto, J. N. \& Vitali, M. (2014). Tribu Astereae. En Zlloaga, F., Belgrano, M. \& A. Anton (eds.), Flora vascular de la República Argentina 7(1): Dicotyledoneae-Asteraceae (Anthemideae a Gnaphalieae), pp. 38-246. Instituto de Botánica Darwinion, Buenos Aires.

Shah, N. Z., Muhammad, N., Azeem, S., Khan, A. Z., Samie, M, \& Khan, H. (2013). Antimicrobial and phytotoxic properties of Conyza bonariensis. Pharmacy and Pharmacology Research 1: 8-11.

Thabit, R. A. S., Cheng, X. R., Tang, X., Sun, J., Shi, Y. H. \& LE, G. W. (2015). Antioxidant and antibacterial activities of extracts from Conyza bonariensis 
growing in Yemen. Pakistan Journal of Pharmaceutical Sciences 28: 129-134.

https://www. ncbi.nlm.nih.gov/pubmed/25553691

ThÉвAUD, C. \& Аввотт, R. J. (1995). Characterization of invasive Conyza species (Asteraceae) in Europe: quantitative trait and isozyme analysis. American Journal of Botany 82: 360-368. https://doi.org/10.1002/j.1537-2197.1995.tb12640.x

Urdampilleta, J. D., Amat, A. G. \& Bidau, C. (2005a). Karyotypic and studies and morphological analysis of some reproductive features in five species of Conzza (Asteraceae: Astereae) from Northeastern Argentina. Boletín de la SociedadArgentina de Botánica 40: 91-99.

Urdampilleta, J. D., Amat, A. G., Bidau, C. J. \& Kolb Koslobsky, N. (2005b). Biosystematic and chemosystematic studies in six South American species of Conyza (Asteraceae). Boletín de la Sociedad Argentina de Botánica 40: 101-107.

Ustarroz, D., Puricelli, E., Rainero, H. P. \& Bellon, D. (2010). Control de rama negra Conyza bonariensis (L.) Cronq. con glifosato en distintos estados de desarrollo de la maleza. Revista Agromensajes 30: 12-14.
Wu, H. (2007). The biology of Australian weeds 49. Conyza bonariensis (L.) Cronquist. Plant Protection Quarterly 22: 122-131.

Wu, H., Walker, S., Robinson, G. \& Coombes, N. (2010). Control of flaxleaf fleabane (Conyza bonariensis) in wheat and sorghum. Weed Technology 24: 102-107. https://doi.org/10.1614/WT-09-043.1

Wu, H., \& ZHU, X. (2014). Who's who in the fleabane (Conyza spp.) family? En BAKER, M. (ed.), Proceedings of the 19th Australasian Weed Conference (2014): Science, Community and Food Security: the Weed Challenge, pp. 157-160. Tasmanian Weed Society Inc., Hobart.

Zahoor, A., Siddiqut, I. N., Khan, A., Ahmad, V. U., Ahmed, A., Hassan, Z., Khan, S. S. \& Iqbal, S. (2010). Two new glycosides from Conyza bonariensis. Natural Product Communications 5: 1099-1102.

https://doi.org/10.1177/1934578X1000500724

ZarLavSKY, G. E. (2014). Histología vegetal: técnicas simples y complejas. Sociedad Argentina de Botánica, Buenos Aires. 